\title{
Perceptions of Child Weight Status by Parents of Children on Medicaid
}

\author{
Jennifer G. Brannon, M.D., Carolyn R. Ahlers-Schmidt, Ph.D., \\ Mark Harrison, M.D. \\ University of Kansas School of Medicine-Wichita \\ Department of Pediatrics
}

\begin{abstract}
Background: Parental perception of child's size has been evaluated in previous studies, but the degree of inaccuracy has been overlooked. In addition, parents of children on Medicaid may be more likely to have inaccurate perception of their child's size. The objectives of this study were to assess the rate of overweight children, document the degree of discrepancy between parents' perceptions and their children's actual weight status, and identify factors related to inaccurate parental perception in a population predominantly insured by Medicaid.

Methods: Participants in the cross-sectional survey included 241 parents of children age three to 12 years, who were English or Spanish speaking, and at least 18 years of age. Surveys asked parents to identify their child's size based on a 5-point likert-type scale.

Results: A Body Mass Index (BMI) at the $95^{\text {th }}$ percentile or above was found for $30.3 \%$ of children. Parents were only correct $39.8 \%$ of the time when describing their child's weight status. In fact, 39.4\% underestimated their child's weight by one BMI category, $17.4 \%$ by 2 categories, and $1.7 \%$ by 3 categories. Parental accuracy decreased as child's weight status increased. No other measured characteristics significantly impacted parental accuracy.

Conclusions: Children on Medicaid have high levels of overweight and nearly $20 \%$ of parents underestimated their child's size by at least 2 BMI categories. Parental perception needs improvement before interventions are likely to be effective. KJM 2009; 2(4):78-86.
\end{abstract}

\section{Introduction}

One of the major health concerns facing children today is the rising epidemic of obesity. Overweight children face a plethora of physical issues that can affect them for the rest of their lives, ${ }^{1,2}$ including type 2 diabetes, hypertension, dyslipidemia, hepatic steatosis, cholelithiasis, sleep apnea, menstrual abnormalities, impaired balance, and orthopedic problems. ${ }^{2}$ In addition, a social stigma is associated with larger body mass that may result in teasing, stereotyping, discrimination, and social marginalization. ${ }^{2,3}$ These social issues may increase depression and anxiety, while decreasing esteem ${ }^{2}$ and perceived cognitive and physical ability, further impairing overall quality of life.

Institutions such as government, public health programs, and school systems, as well as individual health care workers continue to combat the growing prevalence of childhood obesity, but parent's involvement is instrumental in helping children stay healthy. Children whose mothers perceived them as overweight as infants or toddlers lost more weight by the time they were seven than children whose mothers perceived them as just right or underweight. ${ }^{5}$ Also, parents were more likely to actively address their child's excess weight if they perceive their child's weight as a health problem.

Studies in the United States ${ }^{6-12}$, Australia $^{13,14}$ Argentina $^{15}$, Canada ${ }^{16}$, Germany $^{5}$, Italy ${ }^{17}$, New Zealand ${ }^{18}$, and the United Kingdom ${ }^{19,20}$ have assessed parents' perceptions of their child's weight and found between $38 \%^{5}$ and $94 \%{ }^{19}$ of parents were unable to assess their child's weight 
accurately. Several predictors of accuracy have been identified, including child's age $^{1,5,11,14}$, gender $^{11,16,20}$, ethnicity ${ }^{16}$, and Body Mass Index (BMI) ${ }^{7,18,19}$.

While many studies have looked at predictors of inaccuracy, few have measured the degree of inaccuracy. It can be extrapolated from Eckstein et al. ${ }^{6}$ that $2 \%$ of respondents whose children were a little overweight to overweight classified their child as underweight to a little underweight. Miller and colleagues ${ }^{18}$ found that $6 \%$ of parents under-classified their child's weight by two BMI categories. However, neither of these studies actually examined how far off parental perception was from reality. The only identified study that looked at degree of inaccuracy based the comparison on a visual analog scale of measurement. ${ }^{7}$ If the child's actual BMI was greater than or equal to the 95th percentile, $89.5 \%$ of parents were inaccurate by 30 percentage points or more, suggesting at least a two category discrepancy. However the visual analog scale only included the anchors of "Extremely underweight" and "Extremely overweight" so parents may not have been aware of which category their response would fall.

Degree of inaccuracy is an important component in understanding parental perception of child weight and additional research is warranted. Greater variance between parental perception and actual child size may indicate a need for a paradigm shift to improve parental understanding of child weight issues. Helping parents accurately understand their child's size may improve adherence to and efficacy of interventions to decrease child weight and improve health. However, before parental inaccuracy can be addressed, the degree to which parents misidentify their child's size must be understood.

Parents of children who receive Medicaid may be at increased risk for inaccurate perception of child weight. Children with Medicaid or no insurance have greater morbidity and mortality than children on private health insurance ${ }^{21}$ and are more likely to be diagnosed overweight. $^{22}$ In addition, children on Medicaid exhibit lower literacy levels than the general population and may have more difficulty understanding health-related materials. $^{23}$

In previous studies, maternal perception of child weight was assessed in an urban Women, Infants and Children (WIC) program $^{8}$ and in a Head Start program ${ }^{9}$. Both populations often rely on Medicaid for their health care needs, ${ }^{24,25}$ however, both studies were limited to Hispanic populations. Wald et al. ${ }^{10}$ looked at parental perceptions in a pediatric primary care setting, but only a third utilized Medical Assistance. Further investigation is needed to determine accuracy of parental perception of weight status in a Medicaid population.

The purpose of this study was to assess the rate of overweight children, the level of discrepancy between parents' perceptions and their children's actual weight status, and factors related to inaccurate parental perception in a population predominantly insured by Medicaid.

\section{Methods}

Data instrument. A one page, multiplechoice survey was developed regarding health and safety of children. The primary question of interest addressed parental perception of child's weight status. Previous studies used several methods to assess parental perception of weight including a visual analog scale $^{7}$, pictures of children $^{9}$, drawings of children ${ }^{6}$, yes/no questions ${ }^{8,11}$, and four-point likert-type questions ${ }^{10,15,18}$. However, the most commonly used format involved a five-point likert-type question ${ }^{5,6,12,14,16,17,19,20,26,27}$ which was chosen for this study. Response options 
included: "too skinny", "thin", "just right", "somewhat overweight", and "overweight".

The secondary set of questions included topics such as nutritional habits (servings of fruit and vegetables, frequency of fast food use), helmet use, hours of television viewed, hours of sleep per night, time spent in exercise, neighborhood safety, and proximity to closest park. These questions were included to allow parents to answer the survey without bias towards weight issues. $^{7,28}$

The survey was available in English and Spanish and written below the $6^{\text {th }}$ grade language level, as recommended for comprehension in at-risk populations. ${ }^{29}$ Surveys were collected from March to August of 2007. Institutional Review Board approval was obtained from the medical school and the hospital where the ambulatory pediatric services were provided.

Data collection. Parents had to be English or Spanish speaking, at least 18 years old, and the parent of a child age three to 12 years with an appointment at the Wesley Pediatrics Clinic (WPC). WPC provides services to many of the underserved children in Sedgwick County. Approximately $95 \%$ of patients at WPC have Medicaid benefits. Physicians staffing the clinic were pediatric and internal medicine/pediatric residents working under the supervision of pediatric faculty from the University of Kansas School of MedicineWichita.

The survey was distributed to parents upon arrival for their child's scheduled appointment. An information sheet attached to the survey explained the study goals and consent for responses to be used for research purposes was implied by survey completion. Parents were blinded to the exact topic of study to avoid bias. Surveys were completed in the waiting room and given to the child's nurse when the patient was called to an exam room. Patients were included in the study regardless of the reason for seeking medical care.

WPC staff performed routine height and weight measures per clinic procedures. Physical measurements were collected the same day the survey was completed. Following weight and height measurement, WPC staff placed the survey in a closed collection box.

Variables and definitions. Body Mass Index (BMI) was calculated for the patients by taking the weight in kilograms divided by the square of height in meters $\left(\mathrm{kg} / \mathrm{m}^{2}\right)$. Patient BMI results were classified into groups as follows: underweight (BMI less than $5^{\text {th }}$ percentile), normal (BMI $6^{\text {th }}$ through $84^{\text {th }}$ percentile), at risk of overweight (AROW; BMI 85 ${ }^{\text {th }}$ through $94^{\text {th }}$ percentile), overweight (BMI 95 ${ }^{\text {th }}$ percentile and above). Growth charts used to identify BMI percentiles were the May 2000 revised charts by the National Center for Health Statistics (NCHS). ${ }^{30}$

Due to low response rates in the categories of "too skinny" and "thin", parent perceptions of children's weight were truncated from a five-point scale to a fourpoint scale concurrent with the BMI categories reported above. The categories "too skinny" and "thin" were combined to form an underweight group, "just right" became the normal group, "somewhat overweight" became the AROW group, and "overweight" remained the overweight group.

Data analyses. Analyses were conducted using SPSS 15.0 for Windows. ${ }^{31}$ Frequencies, means, and standard deviations were computed for demographic information, while chi-square statistics were computed for categorical and ordinal data. An independent t-test was run to determine the effect of the continuous variable of child age on parental accuracy. 


\section{Results}

Participants. A total of 290 surveys were collected. Only 241, however, included the information necessary to study parent perception of child's weight status, child's weight, and height. Children were age three to 12 years with an average age of 6.38 (SD $=2.781)$. Slightly more male $(122 ; 50.6 \%)$ than female children were evaluated. Equal numbers of participants $(31 \%)$ were Hispanic or African American; 21\% were white, $8 \%$ "other", and the remaining $8 \%$ chose not to identify their ethnicity. The majority of surveys completed were in English (83.4\%).

BMI. The rate of overweight children (BMI 95 ${ }^{\text {th }}$ percentile or above) at the WPC was $30.3 \%$ and the highest percentage of overweight children were African-American (Table 1). However, chi-square analysis found no significant difference between ethnic/racial groups $\left(\chi^{2}(9)=9.082, \mathrm{p}=\right.$ 0.430). Similar distributions of BMI were found based on gender; again, no significant difference was found $\left(\chi^{2}(3)=.991, \mathrm{p}=\right.$ $0.803)$.

Table 1. Percent (and number) of children in each BMI group by race and gender.

\begin{tabular}{lccccccc}
\hline & All $^{*}$ & White & $\begin{array}{c}\text { African- } \\
\text { American }\end{array}$ & Hispanic & Other & Male & Female \\
\hline Less than normal & $3.3 \%$ & $5.9 \%$ & $4.0 \%$ & $2.7 \%$ & $0.0 \%$ & $3.3 \%$ & $3.4 \%$ \\
& $(8)$ & $(3)$ & $(3)$ & $(2)$ & $(0)$ & $(4)$ & $(4)$ \\
Normal & & & & & & & \\
& $55.2 \%$ & $62.7 \%$ & $52.0 \%$ & $54.7 \%$ & $35.0 \%$ & $56.6 \%$ & $53.8 \%$ \\
& $(133)$ & $(32)$ & $(39)$ & $(41)$ & $(7)$ & $(69)$ & $(64)$ \\
AROW & $11.2 \%$ & $5.9 \%$ & $10.7 \%$ & $14.7 \%$ & $15.0 \%$ & $12.3 \%$ & $10.1 \%$ \\
& $(27)$ & $(3)$ & $(8)$ & $(11)$ & $(3)$ & $(15)$ & $(12)$ \\
Overweight & $30.3 \%$ & $25.5 \%$ & $33.3 \%$ & $28.0 \%$ & $50.0 \%$ & $27.9 \%$ & $32.8 \%$ \\
& $(73)$ & $(13)$ & $(25)$ & $(21)$ & $(10)$ & $(34)$ & $(39)$ \\
\hline
\end{tabular}

Numbers missing from the total indicate missing data.

Parental perception. Parents of pediatric patients at WPC were only correct $39.8 \%$ of the time when describing perception of their child's weight status (Table 2). In fact, $39.4 \%$ underestimated their child's weight by one BMI category, $17.5 \%$ underestimated by two categories, and $1.7 \%$ underestimated by three categories; in contrast, only $1.6 \%$ overestimated by one category.

To determine whether differences existed in perception based on child characteristics, chi-square analyses were run to compare parental accuracy to child's race, gender, and BMI group, respectively. To avoid expected cell counts less than five, race was limited to Hispanic, white, and African-American. The results by race were not significant $\left(\chi^{2}(2)=5.483, \mathrm{p}=0.064\right)$. Gender also did not significantly affect accuracy $\left(\chi^{2}(1)=0.467, p=0.494\right)$. However, a comparison of normal, AROW, and overweight children found that BMI group was significantly related to parental accuracy $\left(\chi^{2}(2)=66.527, \mathrm{p}<0.001\right)$. 
Table 2. Percent (and number) of children in each BMI group compared to the parents' perceived BMI group.

\begin{tabular}{ll|cccc|c} 
& BMI & Underweight & Normal & Overweight & Obese & $\begin{array}{c}\text { Total } \\
\text { Children }\end{array}$ \\
\cline { 2 - 6 } & Underweight & $2.1 \%(5)$ & $20.7 \%(50)$ & $1.7 \%(4)$ & $1.7 \%(4)$ & $\begin{array}{c}26.1 \% \\
(63)\end{array}$ \\
$\begin{array}{l}\text { Perceived } \\
\text { Parent } \\
\text { BMI }\end{array}$ & Normal & $1.2 \%(3)$ & $34.0 \%(82)$ & $8.7 \%(21)$ & $15.8 \%(38)$ & $\begin{array}{c}59.8 \% \\
(144)\end{array}$ \\
& Overweight & $0.0 \%(0)$ & $0.4 \%(1)$ & $0.8 \%(2)$ & $10.0 \%(24)$ & $\begin{array}{c}11.2 \% \\
(27)\end{array}$ \\
& Obese & $0.0 \%(0)$ & $0.0 \%(0)$ & $0.0 \%(0)$ & $2.9 \%(7)$ & $\begin{array}{c}2.9 \% \\
(7)\end{array}$ \\
\hline & Total Children & $3.3 \%(8)$ & $55.2 \%(133)$ & $11.2 \%(27)$ & $30.3 \%(73)$ & $\begin{array}{c}100 \% \\
(241)\end{array}$ \\
\hline
\end{tabular}

Parents of normal weight children appeared to be the most accurate with $61.7 \%(82 / 133)$ correctly classifying their child, while only $7.4 \%(2 / 27)$ of parents of AROW children, and $9.6 \%(7 / 73)$ of overweight children could classify their child accurately.

Finally, an independent t-test was computed to identify whether the child's age affected parental accuracy. No difference was found between the age of children whose parents accurately classified their weight $(\mathrm{M}=6.50, \mathrm{SD}=0.286)$ and the age of children whose parents were inaccurate $(\mathrm{M}=6.30, \mathrm{SD}=0.230 ; \mathrm{t}(239)=0.555, \mathrm{p}=$ $0.579)$.

\section{Discussion}

BMI. In 2007, the prevalence of overweight was $14.0 \%$ for youths in Kansas and the highest rate belonged to Washington, D.C. at $22.8 \% .^{32}$ For our sample, the rate of overweight was $30.3 \%$, suggesting a much higher rate than the Kansas average and greatly exceeding the highest national rate.

Parental perception. Accuracy of parental perception for a sample of children on Medicaid was extremely poor at less than $40 \%$, however, accuracy was not lower than previously published studies on more general populations. Parents were accurate in identifying their child's size $62 \%$ of the time if the child's BMI was below the $85^{\text {th }}$ percentile, compared with an accuracy of only $9 \%$ when the child's BMI was greater than or equal to the $85^{\text {th }}$ percentile. This supported previous research findings suggesting parents are less accurate as child's weight increases. ${ }^{18,19}$ However, increased accuracy identifying normal weight children may be inflated due to the wider range of weights $\left(6^{\text {th }}\right.$ to $84^{\text {th }}$ percentile) found within this category.

In our study, we were interested in measuring not only the rate of inaccuracy, but also the degree of inaccuracy. We found nearly $2 \%$ of parents were inaccurate by three categories (identifying overweight children as underweight) and over $17 \%$ of parents were inaccurate by two categories (identifying overweight children as normal or AROW children as underweight). These rates are higher than those previously reported in the literature. $6,7,18$ Degree of inaccuracy is important because the less able parents are to perceive their child's true size, the less likely they are to engage in or support interventions to decrease their child's weight. Contrary to previous findings 
our study did not find significant differences in parental perception by gender or age. $^{1,5,14,16}$ One possible reason could be due to differences in children's ages included in the studies. However, differences in findings between our study and previously published studies may have more to do with the characteristics of the parents than the characteristics of the children.

Medicaid recipients throughout the United States tend to be poor, unemployed, and have low educational attainment. ${ }^{23}$ Parents of overweight children with Medicaid may associate with other parents and children in the same socioeconomic group which could influence their perception of normal weight. Low income mothers' beliefs about overweight also appear to differ greatly from those of the medical and health care communities, ${ }^{9,33}$ as growth charts, the most common tool for identifying overweight status, lack face validity for low-income parents. ${ }^{33,34}$ Lower income parents also tend to characterize overweight by functional impairment and felt a child should not be labeled overweight unless mobility is compromised. ${ }^{9,33}$

The only other issue reported as cause for concern about overweight was if a child was being teased and suffering from low self-esteem as a result. ${ }^{9,33}$ Dominant among low-income mothers' beliefs about their children's weight is that growth and weight are predestined, therefore, out of the mother's control. ${ }^{33,35}$ Inaccurate parental beliefs about child weight may lead parents to disregard medical advice as irrelevant if the health professional fails to take into account the individual child and family when making suggestions for remedy. ${ }^{20,27,33}$ However, parents are more likely to identify weight issues in their child if their doctor had addressed the child's weight. ${ }^{27}$

Addressing parental perception of child weight and the ramifications of excess weight is the first step in addressing childhood overweight. It is clear from the current literature that parents do not accurately perceive their child's weight. Nurses, pediatricians, and family physicians must bear the burden of informing and influencing parents of the importance of maintaining a healthy weight, not just in childhood, but throughout adulthood. As researchers, we must develop effective and culturally sensitive scripts for educating parents about their child's weight and the potential health outcomes. ${ }^{8,16}$ The development of effective interventions also is imperative to decrease the growing problem of overweight in our children, including strategies for parents, schools, and public health workers. The results of the current study suggested that parents of children receiving Medicaid may be an ideal population to pilot interventions due to the higher levels of overweight, potential lower levels of literacy, and inaccurate parental perception of weight.

Limitations. There are several limitations to the current study. The crosssectional design does not lend itself to identification of a cause and effect relationship, therefore, we cannot be sure that having AROW or overweight children causes participants to be less accurate in classifying their child's weight. Other factors, such as number of generations in the United States or denial may play a role in decreasing parents' ability to perceive accurately.

While the survey instrument was based on questions from previous studies and pretested with a small group of participants, it was not examined for test-retest reliability. Therefore, we cannot assume that parents would answer the same if the survey was given again. The survey also was missing key demographic questions regarding respondents (i.g., age, relationship to child) due to a copying error. Further, the survey 
was administered at a single facility, which does not allow for generalization to other practices, settings, or populations.

The survey looked at general perceptions of weight and did not attempt to identify cognitive beliefs that might contribute to misperception of weight. Utilizing BMI as a classification tool may have affected results as it does not take into account muscle mass or bone density. Further, the use of arbitrary cut-offs for BMI ranges also may have affected results.

Conclusions. The identification of low rates of accurate parental perception of overweight in Medicaid insured children could help in the development of appropriate

\section{References}

${ }^{1}$ Guo SS, Wu W, Chumlea WC, Roche AF. Predicting overweight and obesity in adulthood from body mass index values in childhood and adolescence. Am J Clin Nutr 2002; 76:653-658.

${ }^{2}$ Institute of Medicine. Childhood Obesity in the United States: Facts and Figures. September 2004. Accessed at: http://www.iom.edu/Object.File/Master/22 /606/FINALfactsandfigures2.pdf.

${ }^{3}$ Strauss RS, Pollack HA. Social marginalization of overweight children. Arch Pediatr Adolesc Med 2003; 157:746752.

${ }^{4}$ Davison KK, Birch LL. Weight status, parent reaction, and self-concept in fiveyear-old girls. Pediatrics 2001; 107:46-53.

5 Kroke A, Strathmann S, Gunther AL. Maternal perceptions of her child's body weight in infancy and early childhood and their relation to body weight status at age 7. Eur J Pediatr 2006; 165:875-883.

${ }^{6}$ Eckstein KC, Mikhail LM, Ariza AJ, et al. Parents' perceptions of their child's weight and health. Pediatrics 2006; 117:681-690.

7 Etelson D, Brand DA, Patrick PA, Shirali A. Childhood obesity: Do parents recognize this health risk? Obes Res prevention strategies as well as treatment strategies for decreasing childhood overweight in this underserved population. When informed, many parents appear surprised to learn how overweight their child is compared to normal and do not identify tactics easily to improve their child's health. Pediatric healthcare providers need to develop successful communication strategies to inform families when their child is overweight and identify appropriate recourse to combat overweight. Future research should work to identify such strategies as well as determine parental characteristics related to inaccurate perception of child's weight.

2003; 11:1362-1368.

${ }^{8}$ Hackie M, Bowles CL. Maternal perception of their overweight children. Public Health Nurs 2007; 24:538-546.

${ }^{9}$ Reifsnider E, Flores-Vela AR, BeckmanMendez D, Nguyen H, Keller C, DowdallSmith S. Perceptions of children's body sizes among mothers living on the TexasMexico border (La Frontera). Public Health Nurs 2006; 23:488-495.

${ }^{10}$ Wald ER, Ewing LJ, Cluss P, et al. Parental perception of children's weight in a paediatric primary care setting. Child Care Health Dev 2007; 33:738-743.

${ }^{11}$ Watkins MG, Clark KM, Foster CM, Welch KB, Kasa-Vubu JZ. Relationships among body mass index, parental perceptions, birthweight and parental weight after referral to a weight clinic. J Natl Med Assoc 2007; 99:908-913.

${ }^{12}$ West DS, Raczynski JM, Phillips MM, Bursac Z, Heath Gauss C, Montgomery BE. Parental recognition of overweight in school-age children. Obesity (Silver Spring) 2008; 16:630-636.

${ }^{13}$ Campbell MW, Williams J, Hampton A, Wake M. Maternal concern and perceptions of overweight in Australian 
preschool-aged children. Med J Aust 2006; 184:274-277.

${ }^{14}$ Crawford D, Timperio A, Telford A, Salmon J. Parental concerns about childhood obesity and the strategies employed to prevent unhealthy weight gain in children. Public Health Nutr 2006; 9:889-895.

${ }^{15}$ Hirschler V, Gonzalez C, Talgham S, Jadzinsky M. Do mothers of overweight Argentinean preschool children perceive them as such? Pediatr Diabetes 2006; 7:201-204.

${ }^{16} \mathrm{He} \mathrm{M}$, Evans A. Are parents aware that their children are overweight or obese? Do they care? Can Fam Physician 2007; 53:1493-1499.

${ }^{17}$ Genovesi S, Giussani M, Faini A, et al. Maternal perception of excess weight in children: A survey conducted by paediatricians in the province of Milan. Acta Paediatr 2005; 94:747-752.

${ }^{18}$ Miller JC, Grant AM, Drummond BF, Williams SM, Taylor RW, Goulding A. DXA measurements confirm that parental perceptions of elevated adiposity in young children are poor. Obesity (Silver Spring) 2007; 15:165-171.

${ }^{19}$ Carnell S, Edwards C, Croker H, Boniface D, Wardle J. Parental perceptions of overweight in 3-5 y olds. Int $\mathrm{J}$ Obes (Lond) 2005; 29:353-355.

${ }^{20}$ Jeffery AN, Voss LD, Metcalf BS, Alba S, Wilkin TJ. Parents' awareness of overweight in themselves and their children: Cross sectional study within a cohort (EarlyBird 21). BMJ 2005; 330:2324.

${ }^{21}$ Todd J, Armon C, Griggs A, Poole S, Berman S. Increased rates of morbidity, mortality, and charges for hospitalized children with public or no health insurance as compared with children with private insurance in Colorado and the United States. Pediatrics 2006; 118:577-585.
${ }^{22}$ Hampl SE, Carroll CA, Simon SD, Sharma V. Resource utilization and expenditures for overweight and obese children. Arch Pediatr Adolesc Med 2007; 161:11-14.

${ }^{23}$ Weiss BD, Blanchard JS, McGee DL, et al. Illiteracy among Medicaid recipients and its relationship to health care costs. J Health Care Poor Underserved 1994; 5:99111.

${ }^{24}$ D'Angelo D, Williams L, Morrow B, et al. Preconception and interconception health status of women who recently gave birth to a live-born infant--Pregnancy Risk Assessment Monitoring System (PRAMS), United States, 26 reporting areas, 2004. MMWR Surveill Summ 2007; 56:1-35.

${ }^{25}$ US Department of Health and Human Services. The 2006 HHS Poverty Guidelines: One Version of the [U.S.] Federal Poverty Measure. January 24, 2007. Accessed at: http://aspe.hhs.gov/ poverty/06poverty.shtml.

${ }^{26}$ Baughcum AE, Chamberlin LA, Deeks CM, Powers SW, Whitaker RC. Maternal perceptions of overweight preschool children. Pediatrics 2000; 106:1380-1386.

${ }^{27}$ Rhee KE, De Lago CW, Arscott-Mills T, Mehta SD, Davis RK. Factors associated with parental readiness to make changes for overweight children. Pediatrics 2005; 116:e94-101.

${ }^{28}$ Burdette HL, Whitaker RC. A national study of neighborhood safety, outdoor play, television viewing, and obesity in preschool children. Pediatrics 2005; 116:657-662.

${ }^{29}$ Calderón JL, Zadshir A, Norris K. Structure and content of chronic kidney disease information on the World Wide Web: Barriers to public understanding of a pandemic. Nephrol News Issues 2004; 18:76, 78-79, 81-84.

${ }^{30}$ Centers for Disease Control and Prevention. National Center for Health 
Statistics. National Health and Nutrition Examination Survey: Clinical Growth Charts. January 11, 2007. Accessed at: http://www.cdc.gov/nchs/about/major/nha nes/growthcharts/clinical_charts.htm.

${ }^{31}$ SPSS Inc. SPSS 15.0 for Windows. [computer program]. Chicago: SPSS Inc., 2006.

${ }^{32}$ Trust for America's Health. Kansas Adults 27th Most Obese in Country; Youth 24th Most Overweight. Trust for America's Health Reports. Accessed at: http://healthyamericans.org/reports/obesity 2007/release.php?StateID=KS.

Keywords: body weight, child, parents, Medicaid, perception
${ }^{33}$ Jain A, Sherman SN, Chamberlin LA, Carter Y, Powers SW, Whitaker RC. Why don't low-income mothers worry about their preschoolers being overweight? Pediatrics 2001; 107:1138-1146.

${ }^{34}$ Murnan J, Price JH, Telljohann SK, Dake JA, Boardley D. Parents' perceptions of curricular issues affecting children's weight in elementary schools. J Sch Health 2006; 76:502-511.

${ }^{35}$ Jackson D, McDonald G, Mannix J, Faga P, Firtko A. Mothers' perceptions of overweight and obesity in their children. Aust J Adv Nurs 2005; 23:8-13. 